\title{
Evolución de las técnicas de reproducción de mapas
}

Fernando Olmedo Granados, Licenciado en Geografía e Historia

La publicación en 1472 de un sencillo diagrama en xilografía de apenas $65 \mathrm{~mm}$ de diámetro, correspondiente al mapamundi tripartito de "T en 0" inserto en la edición de las Etimologías del obispo Isidoro de Sevilla, estampada por Günther Zainer en Augsburgo dicho año, aun cuando revista cierto carácter anecdótico, marca un hito en la historia de la cartografia, por estar considerado el primer "mapa" impreso en Europa. Además de las connotaciones que, por su origen, comporta con respecto a Andalucia, la aparición de este modesto pero significativo grabado principia la serie de trascendentales cambios que tuvieron lugar en el campo cartográfico a partir de entonces, gracias a la generalización, en paralelo con el avance de la imprenta, de los procedimientos de producción de imágenes múltiples, repetibles con exactitud, que se convertirian en "el motor de una verdadera democratización icónica" (RAMÍREZ, 1976: 24) y de la expansión iconográfica que, como rasgo esencial de cultura occidental postmedieval, llega hasta el día de hoy.

Frente al corto número de manuscritos que integran la producción cartográfica hasta la segunda mitad del siglo XV, al requerir materiales valiosos y un considerable esfuerzo de artífices muy especializados por cada ejemplar, restringiendo así su alcance a círculos muy reducidos, la aplicación a la cartografía de sistemas mecánicos de reproducción potenció considerablemente su accesibilidad al disminuir su coste y multiplicar, por tanto, su circulación. Un hecho que, por sí mismo, contribuyó, por un lado, a la consolidación y aceptación entre la sociedad de la mera "idea" de mapa y a su creciente propagación y uso con los más diversos propósitos (científicos y eruditos, de utilidad aplicada, simbólicos, representativos...), y, por otro, proporcionó un medio de transmisión de conocimientos más estable y fiable -aunque sólo relativamente- sobre el que cimentar futuros progresos, habida cuenta de su capacidad de suministrar una imagen idéntica simultáneamente a un amplio número de destinatarios, sustrayéndose al elevado grado de distorsión de que eran susceptibles las copias manuales'

\section{EL GRABADO EN MADERA Y EN METAL}

Tan sólo un lustro separa la introducción de las dos técnicas fundamentales de reproducción -grabado en relieve, en madera, y en hueco, en metal- llamadas a predominar en la cartografía impresa durante más de tres siglos, hasta el siglo XIX: si en 1472 se estampaba el citado mapamundi de Isidoro de Sevilla a partir de un bloque de madera, en 1477 salía a la luz una edición de la Cosmographia de Claudio Ptolomeo, publicada en Bolonia por Domenico de Lapis, con 26 mapas impresos a base de planchas de cobre grabadas.

La técnica de grabar en relieve consistía en tallar con instrumentos cortantes (cuchillas, gubias, etc.) una matriz de madera (homogénea, dura, de frutales $u$ otros árboles), eliminando parte de su materia para reservar en relieve los elementos de la imagen (líneas, puntos, letras), por lo que se conoció como grabado en madera o xilografía. La manera principal de esta técnica era la xilografía "a fibra" o "al hilo", la talla de tacos de madera cortada en el sentido de la veta. A fines del siglo XVIII el británico Thomas Bewick desarrolló la técnica del grabado en madera a "contrafibra" o "a testa", con bloques de madera cortados transversalmente a la veta, trabajados a buril, que, empleado en ilustraciones, tuvo escasa aplicación en el ámbito cartográfico. Tras entintarse la superficie en relieve de la matriz de madera, la imagen se trasladaba al papel aplicando presión con una prensa convencional.

En el grabado en hueco sobre metal o calcográfico, derivado de las prácticas de orfebres y artesanos del metal, el procedimiento era inverso: la imagen se perfilaba tallando surcos o trazos en profundidad sobre una lámina metálica pulida - de cobre sobre todo hasta el siglo XIX- mediante su incisión directa con instrumentos punzantes (buriles, punta seca, etc.) o su incisión indirecta (al aguafuerte, con ácidos corrosivos que atacan la matriz), combinándose en ocasiones ambas maneras. Mediante una cuidadosa aplicación, la tinta se introducía en dichos surcos, se limpiaba el resto de la superficie y, bajo la enorme presión de una prensa especial de rodillos denominada tórculo, el papel humedecido absorbía la tinta alojada en los surcos y reproducía la imagen de la lámina. Como innovación en el campo de la calcografía surgió el grabado en acero, inventado en 1792 por el norteamericano Jacob Perkins para imprimir billetes de banco y adaptado en la década de 1820 por los británicos Ch. Warren y Ch. Heath para estampar ilustraciones, técnica que, en lugar de una lámina de cobre, empleaba como matriz una plancha de acero, cuya dureza permitía incisiones de extraordinaria nitidez, finura y detalle, aunque de aspecto frío, y tiradas muy copiosas con un desgaste mínimo. Desde el segundo tercio del XIX se usó ante todo en obras cartográficas divulgativas de mediano y pequeño formato. 
En términos comparativos, el grabado en madera ofrecía las ventajas de la baratura de sus materiales, escaso desgaste de la matriz, así como la posibilidad de incorporar tipografía o estereotipos para las leyendas en el mismo bloque y de estamparse por simple imposición o con prensas de imprenta, facilitando la tirada conjunta de imágenes y textos, por lo que se utilizó con profusión para libros ilustrados. En contrapartida, la talla era laboriosa y dificil, propensa a las irregularidades, con un acabado que constreñia los matices y el nivel de detalle, adoleciendo de cierta rigidez y tosquedad en su apariencia. El grabado en metal, a su vez, implicaba un proceso más complejo y costoso, por el alto precio del cobre de las planchas, la fatiga a que se veian sometidas, limitando las tiradas u obligando a regrabarlas, la dificultad y tiempo que requerían algunas operaciones, el número de artífices y operarios especializados necesarios y la exigencia de prensas especiales. Compensaba el resultado, sin embargo, por su versatilidad plástica, la finura de las terminaciones y el amplio registro de matices y pormenores que confería a la estampa, cualidades que hacian del grabado calcográfico el medio más idóneo para la reproducción de cartografía.

Las dos técnicas coexistieron desde un principio siguiendo cursos paralelos, aunque desde el último tercio del siglo XVI el grabado en metal pasó a convertirse en la más habitual para la cartografía impresa, quedando el grabado en madera relegado a ilustraciones de libros y modestas estampas en formato menor. De hecho, en un repertorio de 165 mapas de ámbito regional referentes a Andalucía estampados entre los siglos XV y XVIII, los grabados en madera apenas suman el 2,5\%, siendo todos anteriores a mediados del XVI y correspondiendo los demás a grabados calcográficos, entre ellos la primera representación impresa de una porción de la región andaluza, el mapa de Jerónimo de Chaves publicado por A. Ortelius en $1579^{2}$.

La estampación se efectuaria, salvo algunas excepciones, sobre papel fabricado a mano a partir de fibras vegetales y textiles (lino, cáñamo, trapos...), reconocible por la pauta de líneas (verjuras) verticales y horizontales que le daba el proceso de manufactura, normalmente de tono blanco natural. En la segunda mitad del siglo XVIII se incorporó el papel vitela o avitelado, de textura más homogénea, y desde los comienzos del XIX, el papel continuo o de fabricación industrial, caracterizado por el progresivo añadido de otras cargas, agentes químicos y fibras de celulosa, hasta convertirse ésta, desde mediados de dicha centuria, en la materia primordial de la pasta de papel. La tinta utilizada, similar a la de la imprenta y con una amplia variedad de recetas, era de base grasa, en principio con aceites (de nuez, linaza, etc.), pigmentos (negros "de humo", "de viñas"...) y aditivos naturales, sustituidos posteriormente por ingredientes sintéticos.

Desde fechas tempranas se procuró asimismo sumar el color a las imágenes monocromas de los grabados. Junto a iniciativas episódicas como la impresión superpuesta de planchas de madera con distintos tonos - negro y rojo usualmente-, la
El mapa más grande de Andalucía: entre 1987-1992 se hizo el mapa más grande de Andalucia: es el Mapa Topográfico de Andalucia 1:10.000 (MTA10), con 2.745 hojas que si se unieran todas formarian un mapa de $30 \times 53 \mathrm{~m}$

práctica más común fue la iluminación de la estampa a pincel. En principio se siguió el estilo de las miniaturas medievales, con densas masas de color sobre extensas superficies que casi convertian la estampa en una pintura, ocultando parte de sus trazados, pero desde fines del XVI se impuso una técnica de coloreado a base de aguadas de gradaciones más sutiles, paletas más matizadas y coberturas transparentes.

La frecuente realización de varias tareas por las mismas personas en los estadios iniciales de la producción de cartografía impresa pronto dejó paso a una diversificación y especialización de funciones al aumentar su volumen y transformarse en un ramo de actividad de cariz industrial, diferenciándose diversos artífices y talleres dedicados a los distintos tramos del proceso productivo, a veces agrupados en grandes establecimientos editoriales que lo abarcaban al completo. Los diseños originales de geógrafos, cartógrafos y artistas - cuyas autorias, en caso de especificarse, se recogian bajo las expresiones latinas auctore, formis, invenit, delineavit, designavit, effigiavit, y sus equivalentes vernáculas- se volvían a perfilar por un dibujante para su traslado a las planchas, acondicionadas previamente por operarios y aprendices. Iniciaban entonces su labor los grabadores, que a menudo se repartian la ejecución de líneas, figuras y letras, ocupándose los menos experimentados de los cometidos más rutinarios; su trabajo se acreditaba con las fórmulas fecit, sculpsit, caelavit, incidit, scripsit (para la letra), "gravó", gravée, etc. Otros operarios procedían luego a la preparación de las láminas, del papel y al entintado, efectuando seguidamente la estampación los encargados de las prensas. Por último, auxiliares del taller completaban el secado y corte de las copias y otras faenas subsidiarias. Llegado el caso, los ejemplares se hacian llegar a iluminadores para su coloreado. Este ciclo, desde la delineación inicial a la iluminación, era dirigido y supervisado en parte o en su totalidad por el impresor y editor, que, a cargo asimismo de la distribución y comercialización, consignaba en las obras el nombre de su firma precedido de excudit, apud, ex officina, ex typis, sumptibus, met privilegie, imprimé, chez, etc.

En cuanto a los principales focos productores de cartografía impresa hasta fines del siglo XVIII, cabe señalar que el propio repertorio de obras de interés para Andalucía desde una óptica 
1. Mapa del sudoeste de la Península lbérica estampado en dos hojas mediante grabado calcográfico en plancha de cobre e iluminado, edición de principios del siglo XVIII de una obra inicialmente publicada en Ámsterdam por Nicolaes Visscher II hacia 1683. Fuente: Regnorum Castellæ Novæ Andalusiæe Granadæe Valentiæe et Murciæe accurata Tabula / Per Nicolaum Visscher. - Amsterdam. - In Frederik den Femtes Atlas Vol. III, pl. 35, Det Kongelige Bibliotek, Copenhagen Department of Maps, Prints and Photographs

2. Mapa de la provincia de Sevilla, coincidente con el antiguo reino, del Atlas von Europa nebst den Kolonien de W. E. August von Schlieben, publicado por G. J. Göschen en Leipzig en 1825. Es el primer mapa de una amplia sección de Andalucía que se conoce impreso en litografía. Fuente: Colección particular 3. Mapa de la sección meridional de España, con inclusión de Andalucía grabado al acero de J. y C. Walker, publicado en Londres en 1831 por la Society for the Diffussion of the Useful Knowledge. Fuente: Biblioteca de Andalucía, Granada, signatura MD-3-2; microficha MIC-E-76
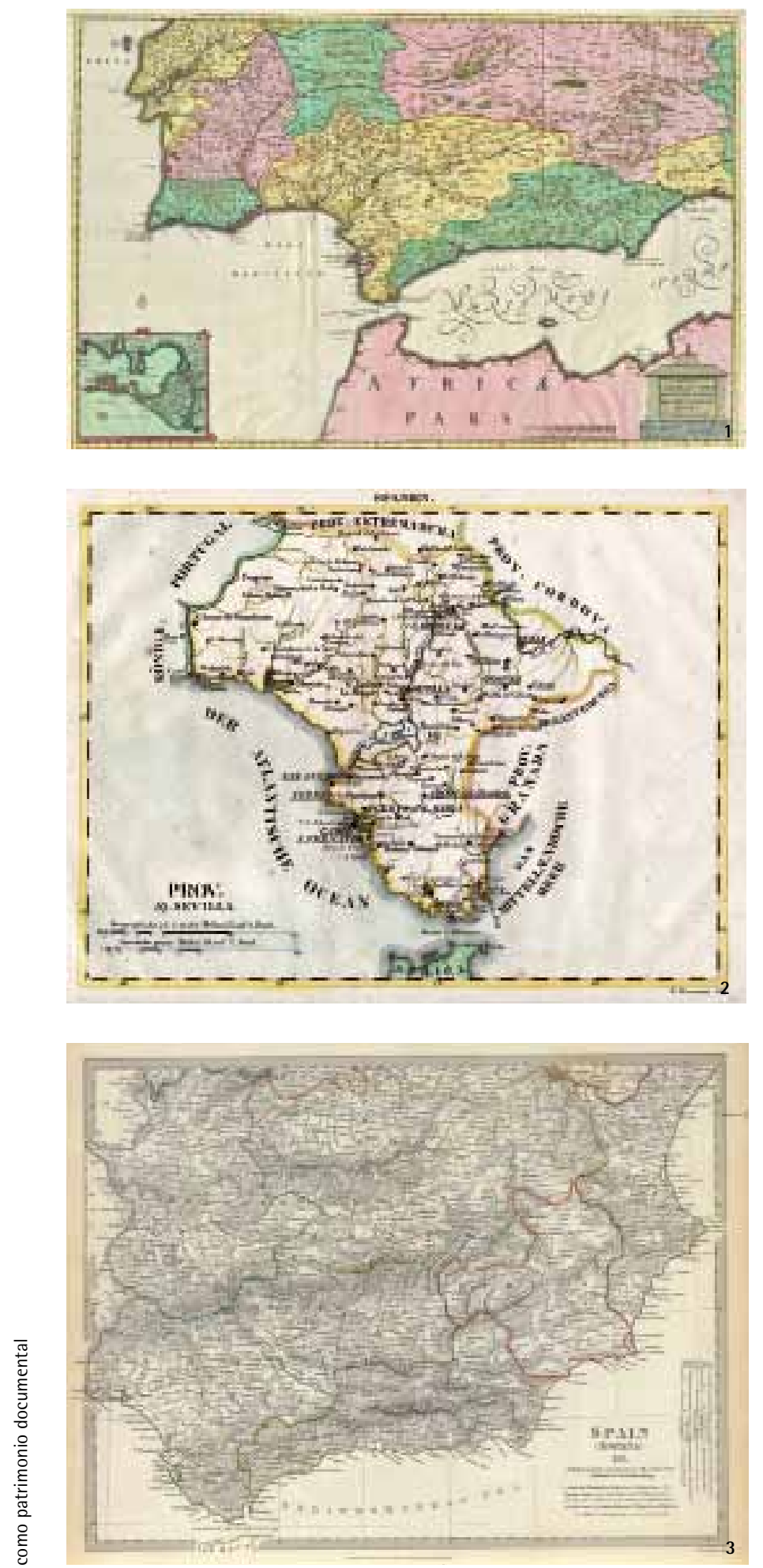

regional ofrece un fiel reflejo de la dinámica general que siguieron. Hasta 1600, los focos de producción de estampas cartográficas se concentran en los Paises Bajos, sur y oeste de Alemania y el norte de Italia, con Amberes, Colonia y Venecia como polos dominantes, junto con una participación menor de talleres españoles. En el siglo XVII se asiste a la indiscutible supremacía holandesa, y de Ámsterdam en particular, junto con el progresivo ascenso de la producción francesa. En el XVIII acontece un cambio sustancial, al observarse la paulatina consolidación de las producciones nacionales y una relativa descentralización de la industria cartográfica a nivel europeo. Gracias al fomento de los gobiernos ilustrados, el mayor porcentaje de la cartografía impresa en esta centuria referente a Andalucia es de procedencia española, seguida de la francesa, con un notable peso, y la generada en otros paises como Holanda, Inglaterra y los estados germánicos.

\section{DE LA LITOGRAFÍA A LAS TÉCNICAS FOTOMECÁNICAS Y DE IMPRENTA}

Desde fines del siglo XVIII las sucesivas innovaciones impulsaron una nueva fase en la evolución de los sistemas de reproducción de materiales cartográficos. La más decisiva fue la invención por Alois Senefelder en 1796 de la litografía, técnica que, a diferencia de las anteriores, no recurria a la talla o incisión de una lámina, sino al trazado de la imagen mediante tintas grasas a pluma y pincel directamente sobre la superficie plana de una piedra calcárea muy pulida. Sometida esta matriz a una serie de procesos químicos basados en el antagonismo entre grasas y agua, al aplicarle la tinta ésta penetraba en los trazados, definiendo la imagen, estampándose en el papel con una prensa litográfica. Sus ventajosos costes, por su economía de tiempo, menor exigencia de mano de obra y capacidad para largas tiradas, junto con su versatilidad y otros méritos desde el punto de vista gráfico, motivaron que la litografía se ensayase enseguida en la reproducción de mapas y que a partir de la década de 1820 se erigiese en el principal medio de la cartografía impresa, en detrimento del grabado calcográfico que hasta entonces había ostentado la preeminencia. Al español Carlos Gimbernat, precisamente, ha de atribuirse la primera iniciativa de aplicar el procedimiento litográfico a la impresión de mapas, según se observa en uno de tierras germanas incluido en su Manual del soldado español en Alemania publicado en Munich en 1807, según sus propio testimonio "gravado en Piedra por Senefelder, inventor del nuevo Arte Polyauthografico, y que es el primer exemplo de la utilidad de esta invención para las obras de Geografía" [sic] (VEGA, 1990: 44).

Varias fórmulas, como, entre otras, el uso de papel autográfico para el traslado a la piedra de dibujos y grabados de topografia, mejoraron y ampliaron el potencial de la litografía en relación con la reproducción cartográfica, con el corolario desde la década de 1830 de la estampación a varias tintas -cromolitografía-, en lí- 
neas o áreas de tonos separados primero y más tarde superpuestos, que, aun sin eliminar inicialmente la iluminación tradicional, supondría a la postre una "revolución" en los recursos gráficos de la cartografía impresa y redundaría en la completa mecanización de sus procesos productivos. El papel determinante que desempeñó la litografía se pone de manifiesto ante el hecho de que casi dos tercios de los mapas de contexto regional y provincial referentes a Andalucia impresos a lo largo del siglo XIX se estamparon mediante este sistema.

Las tendencias anunciadas en el siglo XVIII en cuanto a la distribución de los centros productores de cartografía impresa se acentuaron en el $X_{I}$, incrementándose el protagonismo de las producciones nacionales, favorecidas por las facilidades que desde el punto de vista industrial brindaban las técnicas litográficas. Más de las tres cuartas partes de las estampas de cartografía relativas a Andalucía de esta última centuria se imprimieron en España, con Madrid como foco principal y BarceIona como otro polo de consideración, siendo digna de mención igualmente la incorporación de la producción local de seis de las capitales andaluzas. La aportación foránea, mientras tanto, aunque presente, tenía ya mucha menor incidencia.

Las técnicas basadas en el uso de materiales fotosensibles para el traslado exacto de trazados y otras elaboraciones a soportes litográficos y otros dispositivos de impresión, desarrolladas de manera efectiva desde la segunda mitad del siglo XIX, conducirian a la definitiva modernización de los sistemas de reproducción empleados para la cartografia, hasta compaginarse en fechas recientes con los sistemas digitales. Junto a la continuidad de la litografía, la reproducción de materiales cartográficos se inserta entonces mayoritariamente en los nuevos métodos de la imprenta, por medio de la transferencia a planchas metálicas flexibles, o cilindros, de imágenes descompuestas en tintas directas o en gamas, generalmente cian, magenta, amarillo y negro, para su posterior tiraje en huecograbado, fotograbado, y sobre todo, en offset, sistema en el que la tinta pasa de las planchas a una mantilla de caucho que finalmente imprime el papel.

\section{Notas}

${ }^{1}$ Como es de suponer, los estudios y publicaciones sobre la aparición y repercusiones de la imagen múltiple en términos generales y acerca de la cartografía en particular son extremadamente abundantes. Un repertorio muy completo y actualizado sobre este campo puede hallarse en el apartado bibliográfico del volumen 3 de The History of Cartography editado por David Woodward. Con respecto al "primer mapa impreso", hay que hacer notar que el mapamundi de Isidoro de Sevilla hace al caso tan sólo con respecto a Europa, pues consta que los primeros mapas impresos mediante sistemas de reproducción múltiple se estamparon en China hacia el siglo XII (WOODWARD, 2007: 591-592), si bien su uso y difusión siguieron caminos muy diferentes a los que tuvieron en el ámbito occidental, quedando restringidos a la élites de la Administración.

2 Tanto esta referencia sobre el número y técnicas de estampación empleadas en mapas impresos de ámbito regional referentes a Andalucía como otras consideraciones de similar género que se apuntan más adelante a lo largo de este artículo están basadas en el inventario de 476 piezas cartográficas concernientes a Andalucía realizadas hasta finales del siglo XIX (OLMEDO GRANADOS; CORTÉS JOSÉ, 2011).

\section{Bibliografía}

CAMPBELL, E. (1990) Introduction to the history of cartography. En Cicle de Conferències sobre Història de la Cartografia (1er : 1990 : Barcelona). Introducció general a la història de la cartografia: 1er curs : 30, 31 de gener i 1 de febrer de 1990. Barcelona: Institut Cartogràfic de Catalunya, 1990, pp. 91-137 (Monografies; 7)

GALLEGO GALLEGO, A. (1979) Historia del grabado en España. Madrid: Cátedra, 1979. 544 p.

MORELAND, C.; BANNISTER, D. (1989) Antique Maps. 3a ed. Oxford: Phaidon Press, 1989. 326 p.

OLMEDO GRANADOS, F. (2009) Andalucia. La imagen cartográfica de la Antigüedad a nuestros días. Sevilla: Centro de Estudios Andaluces, Instituto de Cartografía de Andalucía, 2009. 83 p.

OLMEDO GRANADOS, F.; CORTÉS JOSÉ, J. (coord.) (2011) Andalucía. La imagen cartográfica hasta fines del siglo XIX. Sevilla: Instituto de Cartografía de Andalucia, 2011. 568 p.

RAMíREZ, J. A. (1976) Medios de masas e historia del arte. Madrid: Cátedra, 1976. 317 p.

VEGA, J. (1990) Origen de la litografía en España: el Real Establecimiento Litográfico. Madrid: Fábrica Nacional de Moneda y Timbre, 1990. 437 p. VIVES PIQUÉ, R. (2003) Guía para la identificación de grabados. Madrid: Arco Libros, 2003. 319 p

WOODWARD, D. (2007) Techniques of Map Engraving, Printing, and Coloring in the European Renaissance. En WOODWARD, D. (ed.) The History of Cartography. Volume Three. Cartography in the European Renaissance. Chicago; Londres: The University of Chicago Press, 2007, parte 1, pp. 591-610

WOODWARD, D. (ed.) (2007) Cartography in the European Renaissance. Chicago; Londres: The University of Chicago Press, 2007, 2 v., 2180 p. 